\title{
Combination therapy for pulmonary arterial hypertension: still more questions than answers
}

\author{
M.M. Hoeper*, A.T. Dinh-Xuan ${ }^{\#}$
}

\begin{abstract}
As pulmonary arterial hypertension (PAH) is a disease with varying patho-aetiology [1], attempting to arrest its natural progression with a single type of pharmacological molecule might, sometimes, simply not be enough. As with systemic arterial hypertension, combination therapy has been proposed as an attractive, and logical, concept for the treatment of $\mathrm{PAH}$ in the future [2], and this concept is slowly creeping into today's clinical practice. The prospect of combination treatment is, theoretically, highly promising. However, the evidence supporting this concept remains weak.
\end{abstract}

In the past few years, three classes of substances have emerged as effective treatments for PAH: prostanoids, endothelin receptor antagonists, and phosphodiesterase-5 inhibitors [2]. These substances act by different modes of action. Prostanoids replace endogenous prostacyclin, production of which is decreased or absent in the pulmonary vessels of PAH patients [3, 4], and exert vasodilatory and antiproliferative effects predominantly via the intracellular second messenger, cyclic adenosine 5'-monophosphate (cAMP). Endothelin-1 is overexpressed in PAH and causes deleterious effects such as pulmonary vasoconstriction and vascular smooth muscle cell proliferation [5]; effects which are blocked by the administration of endothelin receptor antagonists. Phosphodiesterase-5 inhibitors augment the action of endogenous nitric oxide by inhibiting degradation of the second messenger cyclic guanosine 5'-monophosphate (cGMP) [6], thereby causing pulmonary vasodilatation and inhibition of vascular smooth muscle cell proliferation [7]. Thus, since all these substances act via different intracellular pathways, combining them may exert synergistic effects.

As monotherapy, various prostanoids, as well as the dual endothelin receptor antagonist bosentan and the selective endothelin-A receptor antagonist sitaxsentan, underwent the scrutiny of randomised, placebo-controlled trials to prove beneficial effects on exercise tolerance and haemodynamics in patients with PAH [8-14]. However, except for intravenous epoprostenol, it has not been shown conclusively that longterm survival is also improved. For the time being, the evidence is weakest for the phosphodiesterase-5 inhibitor, sildenafil, since the results of a large randomised multicentre study completed earlier this year have not yet been made public.

Despite these advances, PAH remains incurable. Although long-term improvement or stabilisation can be achieved at least with epoprostenol or bosentan, PAH remains a progressive disease and deterioration eventually occurs in a

\footnotetext{
*Dept of Respiratory Medicine, Hannover Medical School, Hannover, Germany. " Service de Physiologie-Explorations Fonctionnelles, Centre Hospitalier Universitaire Cochin, Assistance Publique-Hôpitaux de Paris, Université Paris V, Paris, France.

Correspondence: M.M. Hoeper, Hannover Medical School, Dept of Respiratory Medicine, Carl-Neuberg-Str. 1, 30625 Hannover, Germany. Fax: 49 5115328536. E-mail: hoeper.marius@mh-hannover.de
}

substantial proportion of these patients. Thus, it came as no surprise that two independent studies addressing survival with intravenous epoprostenol treatment found a strikingly similar $3-y r$ survival rate of $63 \%[15,16]$, which was significantly better than expected from historical data but clearly indicates that there is still a long way to go before acceptable outcome rates are achievable.

Thus, it is understandable that physicians have already started to use combination therapy in desperate clinical situations, often with impressive clinical results. Currently, there are two approaches to combination therapy. One is to start monotherapy with an active substance and to add a second substance when predefined treatment goals are not met. This approach is currently being used by several expert centres and has been shown to yield successful results in small, uncontrolled clinical series [17, 18]. Another concept is to start combination therapy right away, following the principle "hit hard and early".

In this issue of the European Respiratory Journal, HUMBERT et al. [19] present the data from the BREATHE-2 trial, which utilised the second approach, and, in fact, is the first randomised, double-blind, controlled trial to study the effects of combination therapy in PAH. In this rather small study, 33 patients with PAH started on intravenous epoprostenol treatment and were simultaneously randomised to receive either bosentan or placebo. Unfortunately, the results of the study by HUMBERT et al. [19] were nonconclusive. There was a nonsignificant trend toward a greater haemodynamic improvement in the group receiving combination treatment with bosentan and epoprostenol. The mean decrease in total pulmonary vascular resistance was $-36.3 \%$ with bosentan/ epoprostenol compared to $-22.6 \%$ with placebo/epoprostenol $(\mathrm{p}=0.08)$. However, the overall effect on exercise tolerance, dyspnoea-fatigue ratings and functional classification was similar in both groups. A total number of three deaths occurred during or shortly after termination of the study, all in patients exposed to epoprostenol/bosentan. It would be premature to attribute these deaths to combination therapy, since all patients in this study were at high risk because of very severe and progressive pulmonary hypertension, and there was no indication that any death was related to medical treatment. The study was designed by HUMBERT et al. [19] to identify differences in haemodynamic improvements but was underpowered to detect differences in clinical endpoints or survival. Thus, the authors wisely conclude that additional information is needed to evaluate the risk/benefit ratio of combined bosentan-epoprostenol therapy in PAH.

For the present time, many open questions remain. Is combination therapy really superior to monotherapy? Which patients most likely benefit from combination therapy? When is combination therapy best used? Which combinations work best and which combinations might even be harmful? Do we understand the potential pharmacokinetic and pharmacodynamic interactions? What about cost-effectiveness? All these 
questions will have to be answered one by one in welldesigned clinical trials, which is a formidable but feasible task given the international co-operation that has been established among pulmonary arterial hypertension centres throughout the world. Today, the rationale is there to use combination therapy in selected patients, but this approach should be restricted to physicians with a broad expertise in treating pulmonary vascular disease.

\section{References}

1. Eddahibi S, Morrell N, d'Ortho MP, Naeije R, Adnot S. Pathobiology of pulmonary arterial hypertension. Eur Respir $J$ 2002; 20: 1559-1572.

2. Galiè N, Manes A, Branzi A. The new clinical trials on pharmacological treatment in pulmonary arterial hypertension. Eur Respir J 2002; 20: 1037-1049.

3. Christman BW, McPherson CD, Newman JH, et al. An imbalance between the excretion of thromboxane and prostacyclin metabolites in pulmonary hypertension. $N$ Engl J Med 1992; 327: 70-75.

4. Tuder RM, Cool CD, Gearci MW, et al. Prostacyclin synthase expression is decreased in lungs from patients with severe pulmonary hypertension. Am J Respir Crit Care Med 1999; 159: 1925-1932.

5. Lüscher TF, Barton M. Endothelins and endothelin receptor antagonists: therapeutic considerations for a novel class of cardiovascular drugs. Circulation 2000; 102: 2434-2440.

6. Lodato RF. Viagra for impotence of pulmonary vasodilator therapy. Am J Respir Crit Care Med 2001; 163: 312-313.

7. Dinh-Xuan AT. Endothelial modulation of pulmonary vascular tone. Eur Respir J 1992; 5: 757-762.

8. Galiè N, Humbert M, Vachiery JL, et al. Effects of beraprost sodium, an oral prostacyclin analogue, in patients with pulmonary arterial hypertension: a randomized, doubleblind, placebo-controlled trial. J Am Coll Cardiol 2002; 39: $1496-1502$.
9. Barst RJ, McGoon M, McLaughlin V, et al. Beraprost therapy for pulmonary arterial hypertension. $\mathrm{J}$ Am Coll Cardiol 2003; 41: 2119-2125.

10. Barst RJ, Langleben D, Frost A, et al. Sitaxsentan therapy for pulmonary arterial hypertension. Am J Respir Crit Care Med 2004; 169: 441-447.

11. Simonneau G, Barst RJ, Galiè N, et al. Continuous subcutaneous infusion of treprostinil, a prostacyclin analogue, in patients with pulmonary arterial hypertension: a double-blind, randomized, placebo-controlled trial. Am J Respir Crit Care Med 2002; 165: 800-804.

12. Channick RN, Simonneau G, Sitbon O, et al. Effects of the dual endothelin-receptor antagonist bosentan in patients with pulmonary hypertension: a randomised placebo-controlled study. Lancet 2001; 358: 1119-1123.

13. Rubin LJ, Badesch DB, Barst RJ, et al. Bosentan therapy for pulmonary arterial hypertension. $N$ Engl J Med 2002; 346: 896-903.

14. Olschewski H, Simonneau G, Galiè N, et al. Inhaled iloprost for severe pulmonary hypertension. N Engl J Med 2002; 347: 322-329.

15. Sitbon $\mathrm{O}$, Humbert $\mathrm{M}$, Nunes $\mathrm{H}$, et al. Long-term intravenous epoprostenol infusion in primary pulmonary hypertension. Prognostic factors and survival. $\mathrm{J} \mathrm{Am} \mathrm{Coll}$ Cardiol 2002; 40: 780-788.

16. McLaughlin VV, Shillington A, Rich S. Survival in primary pulmonary hypertension: the impact of epoprostenol therapy. Circulation 2002; 106: 1477-1482.

17. Hoeper MM, Taha N, Bekjarova A, Gatzke R, Spiekerkoetter E. Bosentan treatment in patients with primary pulmonary hypertension receiving nonparenteral prostanoids. Eur Respir J 2003; 22: 330-334.

18. Ghofrani HA, Rose F, Schermuly RT, et al. Oral sildenafil as long-term adjunct therapy to inhaled iloprost in severe pulmonary arterial hypertension. $\mathrm{J} \mathrm{Am}$ Coll Cardiol 2003; 42: 158-164.

19. Humbert M, Barst RJ, Robbins IM, et al. Combination of bosentan with epoprostenol in pulmonary arterial hypertension: BREATHE-2. Eur Respir J 2004; 24: 353-359. 